\title{
Analysis of Research Hotspots in Logistics Field based on ESI Highly Cited Paper
}

\author{
Liu Xuan; Huang Jin*; Liu Chang; Liu Wenyan; Yan changyan; Li Xiaohong \\ Library of Huazhong University of Science and Technology \\ Wuhan, Hubei, China \\ hjhust@hust.edu.cn
}

\begin{abstract}
In order to seek clarification of the current research hotspots in logistics field, this paper uses bibliometrics in logistics research. A visualization software Citespace was used to analyze the ESI highly cited paper in 2007-2017 year logistics field in the Web of Science database. This paper makes a deep visual bibliometrics analysis of the research hotspots from the aspects of co-citation network clustering, high-frequency keywords and classical literature, etc, providing reference for further study of logistics.
\end{abstract}

Keywords-Bibliometrics; ESI highly cited paper; Logistics; Visual analysis

\section{INTRODUCTION}

The concept of logistics was first formed in the United States, originated in 1930s. In < Logistics terminology>, published in 1994, the European Logistics Association, ELA defined logistics as "Within a system, the plan, execution and control of transportation, arrangement, and support activities of a person or commodity for a specific purpose". In 1998, the Council of Logistics Management, CLM (its name was changed to Council of Supply chain Management Professionals, CSCMP in January 1, 2005) defined logistics as "In order to meet customer requirements, the process of planning, executing, and controlling in the operations of the supply chain which makes goods, services and related information possible to achieve high efficiency and low cost of the forward and reverse flow and storage between outputs and consumers". Logistics is an important commercial activity, including an organic combination of transportation, storage, loading and unloading, handling, packaging, circulation processing, distributing, information processing and other basic functions. This process not only change the spatial position of physical objects through transportation or handling, adjust both supply and demand in time rhythm differences through storage, but also change the nature of physical or chemical through the circulation process. Its overall goal is to achieve the established level of customer service at the lowest possible total cost [1]. Under these circumstances, the logistics field has become one of the important research subjects. Domestic and overseas scholars have done a lot of research on logistics management from different aspects, with a large number of papers published This paper starting with ESI highly cited paper, using knowledge mapping tools, makes quantitative analysis on research hotspots in logistics field. This paper tries to make a co-citation analysis of citation of node literature by using bibliometrics tools, looking for frontier and hot research

* Huang Jin is corresponding author (e-mail: hjhust@hust.edu.cn) directions in this field, providing theoretical help for future research.

\section{DATA SOURCES AND RESEARCH METHODS}

\section{A. Data sources}

The data of this research comes from Web of Science platform. The Web of Science information retrieval platform is the most common tool for retrieving high-quality literature in the natural sciences, social sciences, arts and humanities. Retrieval strategy: using "logistics" as topic, retrieval in the WOS core collection. The literature coverage time ranges from 2007 to 2017(The deadline is June 30, 2017), 10 years. 124 ESI highly cited papers were obtained.

\section{B. Research methods}

ESI (Essential Science Indicators) has been recognized by academic as an analysis and evaluation tool to measure the performance of scientific research and track the trend of scientific development. ESI high cited paper are the $1 \%$ highest cited paper in various fields. Their content characteristics can reflect the research hotspots and frontiers of subject, and their quantitative characteristics can reflect the level of subject development from a macro perspective.

The map of scientific knowledge is an image showing the development and structure of scientific knowledge [2].

Citespace is one of the most popular tools for mapping knowledge map. Citespace software combines social network analysis, multidimensional scaling analysis and clustering analysis, measuring a particular field of literature (set), to find out the key path of subject evolution and its knowledge inflection point [3]. In this study, Citespace III bibliometric method was used to make the co-citations analysis of ESI high cited paper in logistics field, to identify the main research hotspots of high cited paper.

\section{ANALYSIS OF HOTSPOTS IN LOGISTICS FIELD}

\section{A. High frequency and high centrality keywords analysis}

The analysis of the frequency and centrality of keywords can reflect the attention and development trend in the research field. High frequency keywords represent the hotspots in the research field. The centrality of a keyword is the degree to which a node is passed through the shortest path between the other nodes. The nodes with high centrality play a bridge role 
in the network, which marks an important turning point of the research hotspot, and shows the research hotspots trends in this field. Based on this, this paper makes a keywords cooccurrence analysis of the 124 logistics ESI high cited papers collected in Web of Science in 2007-2017 years. This paper manually removes the same words from the keywords, and then sorts out a data tables of the frequency of keywords (greater than 5), the centrality and the keywords, see table 1.

TABLE I. FREQUENCY AND CENTRALITY OF HIGH-FREQUENCY KEYWORDS (CO-OCCURRENCE FREQUENCY IS GREATER THAN 5)

\begin{tabular}{|c|c|c|c|c|c|}
\hline $\begin{array}{l}\text { Occurrence } \\
\text { frequency }\end{array}$ & centrality & keywords & $\begin{array}{c}\text { Occurrence } \\
\text { frequency }\end{array}$ & centrality & keywords \\
\hline 36 & 0.01 & logistics & 6 & 0.03 & $\begin{array}{l}\text { conceptual } \\
\text { framework }\end{array}$ \\
\hline 25 & 0.03 & model & 6 & 0.01 & $\begin{array}{l}\text { corporate social } \\
\text { responsibility }\end{array}$ \\
\hline 23 & 0 & $\begin{array}{l}\text { supply chain } \\
\text { management }\end{array}$ & 6 & 0.04 & initiative \\
\hline 22 & 0.04 & reverse logistics & 6 & 0.02 & $\begin{array}{l}\text { green supply chain } \\
\text { management }\end{array}$ \\
\hline 19 & 0.01 & performance & 6 & 0.07 & perspective \\
\hline 17 & 0.01 & industry & 6 & 0.05 & product recovery \\
\hline 13 & 0.13 & system & 6 & 0.13 & optimization \\
\hline 12 & 0.05 & management & 6 & 0.01 & social responsibility \\
\hline 12 & 0.05 & sustainability & 6 & 0.05 & cost \\
\hline 11 & 0.02 & literature review & 6 & 0.02 & implementation \\
\hline 11 & 0.04 & supply chain & 5 & 0 & uncertainty \\
\hline 10 & 0.01 & framework & 5 & 0.01 & environment \\
\hline 10 & 0.04 & $\begin{array}{l}\text { environmental } \\
\text { management }\end{array}$ & 5 & 0.02 & china \\
\hline 9 & 0.03 & green & 5 & 0.01 & algorithm \\
\hline 9 & 0.06 & network design & 5 & 0 & integration \\
\hline 9 & 0.07 & bioma & 5 & 0.02 & strategy \\
\hline 9 & 0.03 & network & 5 & 0.02 & supplier selection \\
\hline 8 & 0.05 & design & 5 & 0.19 & risk \\
\hline 8 & 0.04 & $\begin{array}{c}\text { life cycle } \\
\text { assessment }\end{array}$ & 5 & 0.02 & biofuel \\
\hline 8 & 0.01 & firm performance & 5 & 0 & impact \\
\hline 8 & 0.06 & facility location & 5 & 0.05 & $\begin{array}{l}\text { closed loop supply } \\
\text { chain }\end{array}$ \\
\hline 7 & 0.05 & $\begin{array}{l}\text { operations } \\
\text { management }\end{array}$ & 5 & 0.12 & $\begin{array}{l}\text { programming } \\
\text { approach }\end{array}$ \\
\hline 7 & 0.03 & optimization model & 5 & 0.01 & $\begin{array}{l}\text { competitive } \\
\text { advantage }\end{array}$ \\
\hline 7 & 0.12 & genetic algorithm & 5 & 0.01 & $\begin{array}{c}\text { reverse logistics } \\
\text { network }\end{array}$ \\
\hline
\end{tabular}

We extracted the hot technical keywords in the logistics field and classified them as follows: First One is the hot technical words with high centrality. Such as system, optimization, risk, programming approach, genetic algorithm. 
These keywords play an obvious role as a bridge. For example, optimization connects resource allocation and operation research at the same time. With the process of globalization of manufacturing industry, higher requirements have been put forward for logistics punctuality, openness and agility of response to user. Therefore, the importance of logistics system design has become increasingly prominent. Second is the high frequency hot technical words. Such as logistics, model, supply chain management, reverse logistics. This kind of hot words summarizes and generalizes the knowledge structure of this field, and is the theoretical foundation of the research in logistics field. Supply chain management has always been one of the main fields of logistics research. It takes the logistics industry as the object, and realizes the supply chain coordination through the model design of the supply chain process, so as to improve the efficiency of resource operation. The research of reverse logistics is to ensure the specificity and certainty of logistics elements in the stage of "product renewable resources". Third is the hot technical words with both higher frequency and higher centrality. Such as sustainability, environmental management, life cycle assessment, etc. These hot words represent the research hotspots and future research trends in the field of foreign logistics. The related functions of logistics activities, such as transportation, storage, distribution, processing, packaging and so on, often bring huge negative effects on resources and environment because of improper handling. Therefore, sustainable development and environmental management will play an important role in promoting the transformation and upgrading of the logistics industry structure.

\section{B. Research hotspots analysis}

Burst Term refers to the sudden change in frequency of professional terms in different time intervals (Increase sharply). In this study, Citespace is used to make the co-citation analysis of the references of the 124 paper and co-occurrence analysis of Burst Term to find out hot research topics. This research focuses on the hot research contents of the whole period. Therefore, only 1 time zones are divided in the Citespace interface, the time zone span is 10 years (2007 - 2017), "Cited Reference" and "Burst Term" are selected as the node types. Stanford, NLP, Group, Part-of-speech, tagging technology was used to extract terms from Title, Abstract, Author Keywords (DE) and Keyword Plus (ID). And further generate co-word network. After visualization of the analysis results, the clustering analysis of co-citation network is carried out. The cluster tags are extracted from the title of the cited articles and $\mathrm{tf}^{*} \mathrm{df}$ are selected as the tag word extraction method. The results are shown in Figure 1.
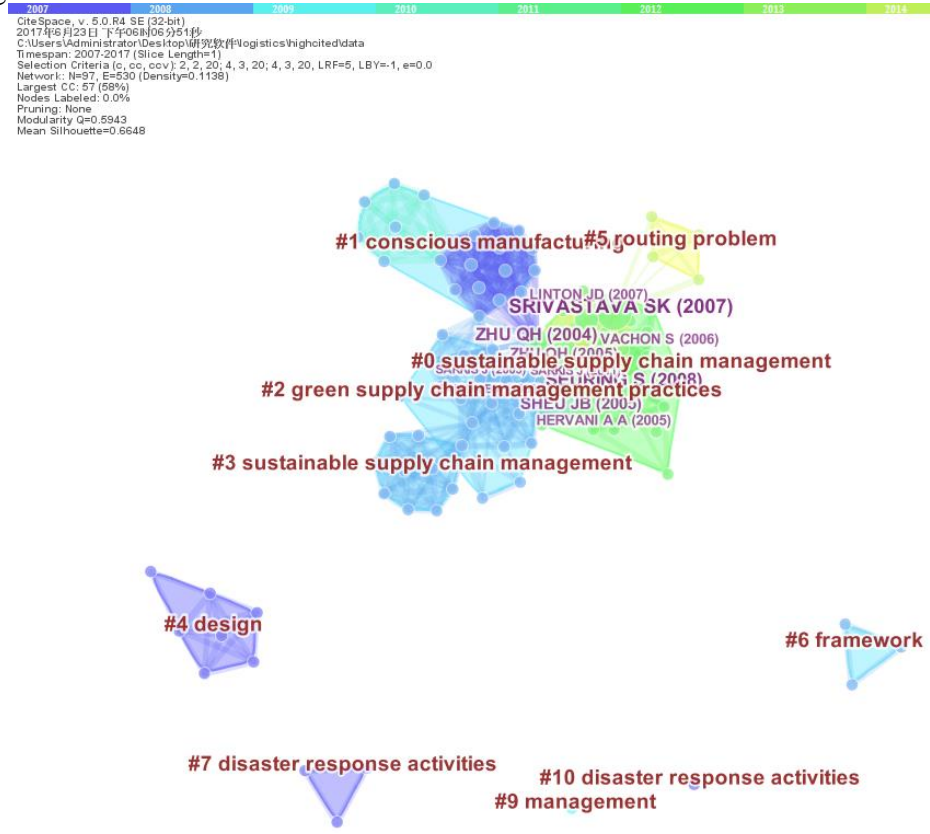

Fig. 1. Research hotspots of ESI highly cited paper in logistics field

According to the network structure and the definition of clustering, Citespace provides two indexes, the module value ( $Q$ value) and the mean silhouette ( $S$ value), to evaluate the clustering effect. $\mathrm{Q}>0.3$ means that the network community structure is significant, and $\mathrm{S}>0.5$ can be considered as a reasonable result. In this clustering, the $\mathrm{Q}$ value is $0.5943, \mathrm{~S}$ value was 0.6648 , which illustrates that the characteristics of literature clusters are obvious, the clustering results have high reliability and the result of the atlas is good. The nodes in Figure 4 include two types: quotation and Burst Term, A total of 10 clusters were found in the Citespace cluster (Each cluster labels are numbered from "\#" and digital Arabia). According to all kinds of clustering labels and Burst Term, and the contents of literature of key nodes within a cluster, we can summarize 4 research hotspots of ESI high cited paper in logistics field.

(1) Sustainable supply chain management: With the increasing pressure and constraint of resources environment, sustainable supply chain management has become the trend of the future development of logistics. Craig R. Carte [4] spanned 
the 20 year time framework to systematically describe sustainable supply chain management. He believes that we should focus on improving the entire supply chain economic, environmental and social performance, identify the key links, develop a practical plan to guide future randomized studies to realize the whole supply chain profit sharing and risk sharing, and innovate management mode. Sarkis [5] have studied that how should the environment oriented reverse logistics practice integrate with the dynamic capabilities of the resources under the pressure of stakeholders.

(2) routing: In order to achieve the goal that reduce logistics activities costs and improve logistics activities efficiency, with the help of linear programming theory and mathematical algorithms, scholars have carried out scientific modeling and optimal design of the nodes, location, processes and routes of the basic logistics activities such as transportation, warehousing and distribution, to establish a timely inventory and delivery system and ensure efficient operation. Scholars use ant colony algorithm, genetic algorithm and analytic hierarchy process to simulate and optimize.

(3) Design and management: Using different methods of data collection and processing, establish a decision model of econometrics and management science, analyze how to drive collaborative management of each dimension. According to the scientific principles, Meryl Brod [6] made data analysis on qualitative concepts problems and frameworks, and evaluate quality and acceptability by empirical research. System dynamics model, chaos model, complex network, innovative lean production theory and model have been highly recognized and widely used.

(4) Disaster response activities: Disaster response activities is a new cross subject, which mainly combines complex science, management science and computer simulation technology. It mainly studies on when natural disasters, accidents, public health incidents and social security incidents and other emergencies occur, how to coordinate the emergency logistics activities, to ensure the emergency supplies arrive at the place of emergency in time. For example, Wei Yi [7] proposed a location allocation model for coordinated logistics support and evacuation operations based on complex networks.

\section{Topic mining on full text of highly cited paper}

We use the most cited ESI highly cited paper on WOS platform "From a literature review to a conceptual framework for sustainable supply chain management" [8] as an object to make topic mining on full text. The paper was published in 2008, and as of June 30, 2017, it was cited 918 times. Using Extract terms from a full text file in Citespace, we can get the thesaurus of this text.

TABLE II. SUBJECT THESAURUS OF MOST HIGHLY CITED PAPER

\begin{tabular}{|c|c|c|c|c|}
\hline tf & idf & tf*idf & clumping & term \\
\hline 58 & 1.39 & 80.41 & 0.98 & supply chain \\
\hline 36 & 1.95 & 70.05 & 0.9 & management \\
\hline 33 & 1.79 & 59.13 & 1.04 & environmental \\
\hline 27 & 2.08 & 56.14 & 0.98 & $\mathrm{gscm}$ \\
\hline 25 & 2.3 & 57.56 & 0.89 & green \\
\hline 24 & 2.4 & 57.55 & 0.83 & practices \\
\hline 24 & 2.3 & 55.26 & 0.88 & sustainability \\
\hline 20 & 2.3 & 46.05 & 1.04 & analysis \\
\hline 17 & 2.56 & 43.6 & 0.98 & performance \\
\hline 13 & 2.89 & 37.57 & 0.95 & $\mathrm{sscm}$ \\
\hline 12 & 2.89 & 34.68 & 1.03 & framework \\
\hline 12 & 2.89 & 34.68 & 1.03 & identified \\
\hline 12 & 2.89 & 34.68 & 1.03 & metrics \\
\hline 7 & 3.4 & 23.81 & 1.01 & implementation \\
\hline 6 & 3.58 & 21.5 & 1.01 & empirical \\
\hline 6 & 3.58 & 21.5 & 1.01 & fuzzy \\
\hline 5 & 3.76 & 18.81 & 1.01 & methodology \\
\hline 5 & 3.76 & 18.81 & 1.01 & manufacturing \\
\hline 5 & 3.76 & 18.81 & 1.01 & network \\
\hline
\end{tabular}

TF means word frequency, the frequency that the entries appear in the paper. idf means the reverse file frequency, the ability to classify entries. The cluping means a cluster, a clustering representation based on the allocation weights of the content bearer words. It can be considered as a classical literature in logistics field which takes over from the past and sets a new course for the future. First of all, it introduces the literature review of sustainable supply chain management, including 191 papers from 1994 to 2007 . Second, it provides a conceptual framework to summarize research in this field, consisting of three parts. Finally, two different strategies are proposed in this literature: (1) Supplier risk management and performance management; (2) Supply chain management for sustainable products. The focus of this paper can be revealed 
by high-frequency words, clusters and content carrying words such as supply chain, sustainability, sustainability, methodology.

\section{CONCLUSION}

This paper using quantitative research and visualization methods, through map of knowledge, makes deep mining to the content characteristics of ESI high cited papers in 2007-2017 years, to reveal their main research hotspots. The research focuses are mainly on high-frequency and high-centrality words, co-citation and Burst Term analysis, and classical literature full text mining and other methods. The research shows that the logistics field presents four research focuses: sustainable supply chain management, routing, design and management, disaster response activities. With the multi polarization development of the global economy and the restriction of the resources carrying environment, the study of the strategy of sustainable development of logistics is worth looking forward to, and the mode expansion and technical means will further expand the scope of logistics services.

\section{REFERENCES}

[1] Management dictionary [Z]. (in Chinese)

[2] Li Xiaotao,Qin Ping,Qian Lingfei. Analysis of the Knowledge Map of the Highly Cited Papers in the Basic Science Index Database [J]. Information Theory and Practice. 2017(02): 111-116 (in Chinese).

[3] Chen Yue,Chen ChaoMei,Liu Zeyuan. The Methodological Function of CiteSpace Knowledge Map [J]. Science Research. 2015(02): 242-253(in Chinese).

[4] Carter C R. Sustainable supply chain management: evolution and future directions[J]. International Journal of Physical Distribution \& Logistics Management.

[5] Sarkis J, Gonzalez-Torre P, Adenso-Diaz B. Stakeholder pressure and the adoption of environmental practices: The mediating effect of training[J]. Journal of Operations Management. 2010, 28(2): 163-176.

[6] Brod M, Tesler L E, Christensen T L. Qualitative research and content validity: developing best practices based on science and experience[J]. Quality of Life Research. 2009, 18(9): 1263-1278.

[7] Wei Y, Zdamarb L. A dynamic logistics coordination model for evacuation and support in disaster response activities [J].

[8] Seuring S, Müller M. From a literature review to a conceptual framework for sustainable supply chain management[J]. 